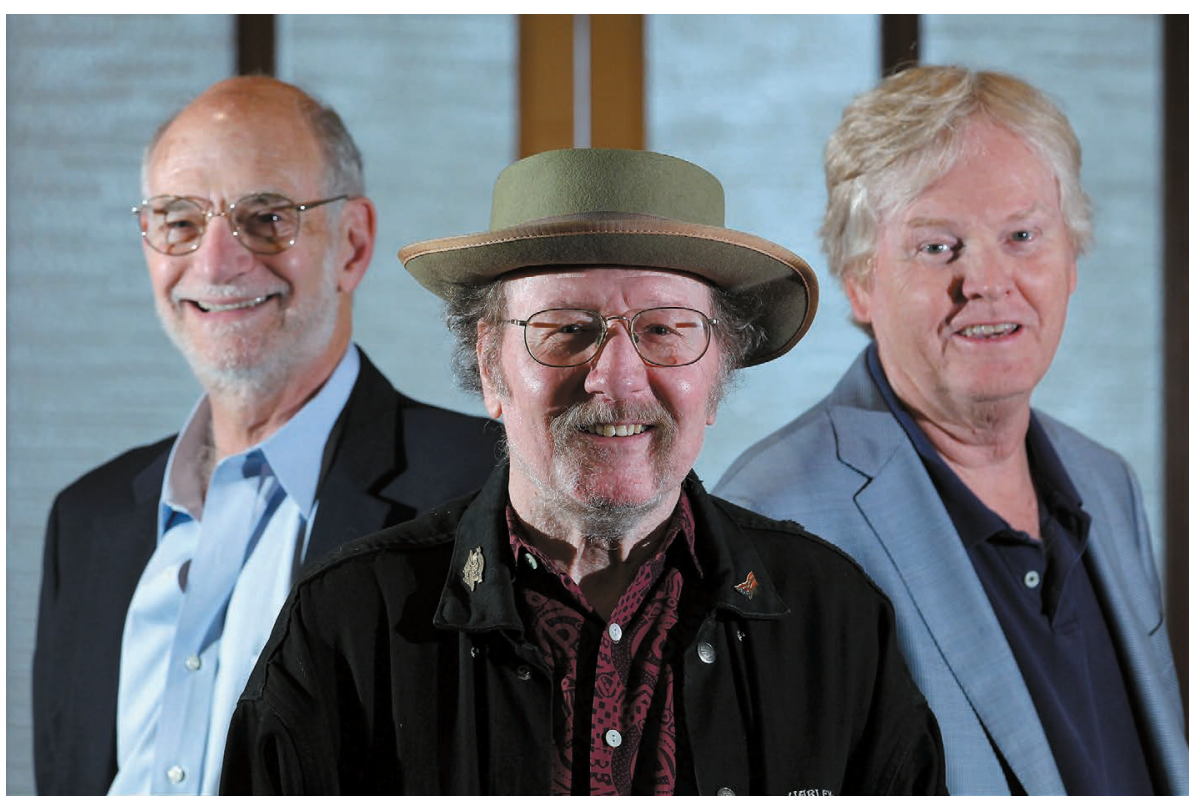

Like clockwork (from left): Michael Rosbash, Jeffrey Hall and Michael Young.

\title{
MOLECULAR BIOLOGY
}

\section{Circadian clocks scoop Nobel prize}

\section{Jeffrey Hall, Michael Rosbash and Michael Young unpicked molecular workings of the daily rhythms of cells.}

\section{BY HEIDI LEDFORD AND EWEN CALLAWAY}

$\mathrm{T}$ hree scientists who studied the workings of organisms' inner circadian clocks have won the 2017 Nobel Prize in Physiology or Medicine. Jeffrey Hall and Michael Rosbash, both at Brandeis University in Waltham, Massachusetts, will split the award of 9 million Swedish kronor (US\$1.1 million) with Michael Young at Rockefeller University in New York City.

Beginning in the 1980s, the three researchers isolated and characterized a gene in fruit flies, called period, that encodes a protein that builds up each night, only to be broken down the following day. In subsequent work, the trio, as well as other scientists, unpicked the molecular regulation of the period gene (and the protein that it encodes, called PER) and identified additional components of the circadian clock.

All multicellular organisms possess circadian clocks, and human versions of the genes that comprise these clocks have been implicated in sleeping disorders and other medical conditions.

Hall, Rosbash and Young have been collecting awards together for the past five years. In
2013, for example, they shared the Shaw Prize in life science and medicine, then worth US\$1 million. That set the expectation that a Nobel might be around the corner, says Herman Wijnen, who studies circadian clocks at the University of Southampton, UK, and was a postdoc in Young's lab. "This has been one that people have been looking out for," he says. "It's been settled in the scientific community that this is the trio."

But Young says he was so stunned by the news that he could barely get his

"This is going
to encourage
more people to
consider the
importance of
time in biology."
shoes on after he found out. "I'd go and I'd pick up the shoes and then I'd realize I need the socks," he said during a press conference. "And then I realized I needed to put my pants on first." The award took Rosbash by surprise, too, says Thomas Perlmann, secretary of the Nobel Assembly, which selects the prizewinners. "I first got hold of Michael Rosbash, and he was silent," says Perlmann. "And then he said, 'you are kidding me."

The work has its roots in genetic screens performed by physicist and molecular biologist Seymour Benzer and geneticist Ronald Konopka, who found fruit-fly mutants with abnormal hatching rhythms. (Benzer died in 2007, Konopka in 2015.) At the time, the idea that behaviour could have a genetic basis was controversial, says Wijnen. Years later, two teams - Young leading one, Hall and Rosbash working together to lead the other - would clone the genes responsible. "That really changed the situation," says Wijnen. "Since then, it has become clear how conserved this system is and how conceptually it could work."

The competition between the two teams - each with ambitions to be first to identify the gene - was initially intense, says Charalambos Kyriacou, a behavioural geneticist at the University of Leicester, UK, who worked with Hall in the late 1970s. "As they got older they mellowed," he says. "They're all good buddies now."

Subsequent work detailed how abundance of the PER protein peaks at night and then declines during the day. Researchers gradually pieced together a model in which the accumulation of PER serves as a signal that represses expression of the gene that encodes it. This type of negative feedback loop would become a prevailing theme in the study of circadian rhythms, as researchers identified additional loops and clock proteins over the years.

Joseph Takahashi at the University of Texas Southwestern Medical Center in Dallas and others extended the work from fruit flies to mammals, and showed that the system is remarkably conserved across species. Researchers have since tied the circadian clock to many aspects of mental and physical wellbeing. "We expose ourselves to inappropriate light, we travel across time zones, we do shift work," says Wijnen. "And all of that is negatively impacting our health."

Takahashi says that he hopes the awarding of the Nobel prize will encourage other researchers to look at how circadian rhythms might affect their experiments, something that he argues is too often ignored. "It's going to encourage more people to actually consider the importance of time in biology," he says.

The links between the circadian clock and human health are so pervasive that medical schools should increase their focus on chronobiology, too, says Martha Merrow, chair of medical psychology at Ludwig Maximilian University of Munich in Germany. This could be either as a speciality in its own right, or incorporated into medical training in other specialities such as endocrinology or rheumatology, she adds. A Nobel prize may give Merrow and her colleagues added force to make that case. Merrow learnt of the news just before an administrative meeting. "I was so breathless, I could hardly go into my meeting," she says. "It's just a fantastic choice. It will be great for our field." 